\title{
Effect of video game playing and a glucose preload on subjective appetite, subjective emotions, and food intake in overweight and obese boys.
}

\begin{tabular}{|r|l|}
\hline Journal: & Applied Physiology, Nutrition, and Metabolism \\
\hline Manuscript ID & apnm-2018-0281.R1 \\
\hline Manuscript Type: & Article \\
\hline Author: & 20-Jul-2018 \\
\hline $\begin{aligned} \text { Complete List of Authors: } \\
\text { Oheller, Brandon ; Mount Saint Vincent University, Department } \\
\text { of Applied Nutrition } \\
\text { Totosy de Zepetnek, Julia; University of Regina Faculty of } \\
\text { Kinesiology and Health Studies, Faculty of Kinesiology and } \\
\text { Health Sciences } \\
\text { Welch, Jo; Dalhousie University, Kinesiology } \\
\text { Rossiter, Melissa; University of Prince Edward Island } \\
\text { Luhovyy, Bohdan; Mount Saint Vincent Univeristy, Applied } \\
\text { Human Nutrition } \\
\text { Brett, Neil; Ryerson University, School of Nutrition, Faculty of } \\
\text { Community Services } \\
\text { Bellissimo, Nick; Ryerson University, School of Nutrition, Faculty } \\
\text { of Community Services }\end{aligned}$ \\
\hline $\begin{array}{r}\text { Is the invited manuscript } \\
\text { for consideration in a } \\
\text { Special Issue? : }\end{array}$ & $\begin{array}{l}\text { Not applicable (regular submission) } \\
\text { Screen Time }\end{array}$ \\
\hline \hline
\end{tabular}


Title: Effect of video game playing and a glucose preload on subjective appetite, subjective emotions, and food intake in overweight and obese boys.

Running title: Pre-meal video game playing and glucose on food intake in boys

\section{Authors:}

Brandon J.F. Gheller ${ }^{1}$, Julia O. Totosy de Zepetnek ${ }^{2}$, Jo M. Welch³, Melissa D. Rossiter ${ }^{4}$, Bohdan Luhovyy ${ }^{1}$, Neil R. Brett ${ }^{5}$, Nick Bellissimo*5

${ }^{1}$ Applied Human Nutrition, Mount Saint Vincent University, 166 Bedford Highway, Halifax, Nova Scotia, Canada, B3M 2J6

${ }^{2}$ Faculty of Kinesiology and Health Studies, University of Regina, 3737 Wascana Parkway, Regina, Saskatchewan, Canada, S4S 0A2

${ }^{3}$ Division of Kinesiology, School of Health and Human Performance, Dalhousie University, 6230 South Street, Halifax, Nova Scotia, Canada, B3H 4R2

${ }^{4}$ Department of Applied Human Sciences, University of Prince Edward Island, 550

University Avenue, Charlottetown, Prince Edward Island, Canada, C1A 4P3

${ }^{5}$ School of Nutrition, Ryerson University, 350 Victoria Street, Toronto, Ontario, Canada, M5B 2K3, 416-979-5000 ext. 3026, nick.bellissimo@ryerson.ca

*Corresponding Author

Registered at clinicaltrials.gov: NCT01750151

Statement of Financial Support: Supported by the Danone Institute of Canada Grant-in aid program; and a publication grant by the Faculty of Community Services, Ryerson University.

Abstract Word Count: 253

Manuscript Word Count: 3895

\section{Abstract}


Video game playing (VGP) is associated with overweight/obesity (OW/OB). VGP and caloric preloads in the pre-meal environment influence short-term food intake (FI) in healthy weight children. Therefore, the purpose of the present study was to examine the effect of premeal VGP and a glucose preload on subjective emotions, subjective appetite, and FI in boys with OW/OB. On four separate mornings, boys with OW/OB $(n=22 ;$ mean \pm SD: age $=$ 11.9 \pm 1.6 years; BMI percentile $=94.3 \pm 3.9)$ participated in four test conditions. Two hours after a standardized breakfast, boys consumed equally sweetened preloads $(250 \mathrm{~mL})$ of sucralose $(0 \mathrm{kcal})$ or glucose $(200 \mathrm{kcal})$, with or without $30 \mathrm{~min}$ of subsequent VGP. FI from an ad libitum pizza meal was measured immediately after all test conditions. Subjective appetite was measured at 0 (baseline), 15, and $30 \mathrm{~min}$. Subjective emotions (aggression, anger, excitement, disappointment, happiness, upset, and frustration) were measured at 0 and 30 min. VGP did not affect FI, but the glucose preload decreased FI compared with the sucralose control $(\Delta=-103 \pm 48 \mathrm{kcal}, p<0.01)$. However, cumulative FI (preload kcal + meal kcal) was $9 \%$ higher after the glucose preload $(p<0.01)$. Subjective appetite increased with time $(p<0.05)$ but was not influenced by preload or VGP. Frustration was the only subjective emotion that increased following VGP $(p<0.01)$. A glucose preload, but not VGP, suppressed FI in boys with $\mathrm{OW} / \mathrm{OB}$, suggesting a primary role of physiological factors in short-term FI regulation.

Keywords: Video Game Playing, Childhood Obesity, Food Intake, Appetite, Screen Time Abbreviations: AA, average appetite; CC, caloric compensation; DTE, desire to eat; FM, fat mass; FFM, fat free mass; FI, food intake; OW/OB, overweight/obese; PFC, prospective food consumption; VAS, visual analog scale; VGP, video game playing

\section{INTRODUCTION}


Associations between sedentary screen-time activities and unfavorable health outcomes (Cameron et al. 2016, Eagle et al. 2012, Hands et al. 2011, Mitchell et al. 2013, Turel et al. 2017) have led to guidelines to limit screen use to less than $2 \mathrm{~h}$ per day, as a way to promote healthier body weights (Strasburger 2004, Tremblay et al. 2011). Video game playing (VGP) contributes to an increasing amount of screen-time use in children and adolescents (Foeher 2010, Turel et al. 2017); VGP in the United States increased from 26 $\mathrm{min} /$ day in 1999 to $73 \mathrm{~min} /$ day in 2009 (Foeher 2010), and in Canada, the average daily time spent VGP among children aged 10- 16 y is $110 \mathrm{~min} /$ day (or 12.8 hours/week) (Carson and Janssen 2012). VGP as a source of screen time exposure for more than one hour daily has been shown to increase the odds of being obese in children aged 7- 9 y (Carvalhal et al. 2007), and the likelihood of being obese nearly doubles with each additional hour per day spent VGP (Stettler et al. 2004).

VGP is thought to contribute to obesity by displacing physical activity, increasing energy intake, or both. Increased consumption of food at mealtime could be due in part to distraction, emotion, or high cognitive loads while engaging in screen-time activities (Bellissimo et al. 2007, Branton et al. 2014, Brunstrom and Mitchell 2006, Mellecker et al. 2010). VGP may act as a distractor by inhibiting satiety (Epstein et al. 2009), and/or altering subjective emotions that contribute to FI regulation (Branton et al. 2014). The impact of VGP before or during mealtime on food intake (FI) in children and adolescents has been mixed. In 15- 19 y old boys with normal weight, pre-meal VGP for 60 min increased subsequent FI by $80 \mathrm{kcal}$ (Chaput et al. 2011), whereas in 13- $17 \mathrm{y}$ old boys with normal weight, 60 min of premeal VGP did not affect FI (Gribbon et al. 2015). We have recently reported decreased FI in 9- 14 y old boys with healthy weight following 30 min of VGP (Branton et al. 2014), suggesting that younger children and adolescents may be less susceptible to overeating in response to VGP compared to older adolescents. 
The preload design is ideal to measure how VGP may affect the physiological FI response of previously consumed calories. In the preload design, participants consume a load of fixed caloric content (the preload) followed by subjective measures of appetite and a meal fed ad libitum (Adolphus et al. 2017, Blundell et al. 2010). Introducing VGP between the preload and the ad libitum meal replicates a real-life scenario where children may have a mid-morning snack, VGP, then consume lunch while also leveraging the preload design to measure the effect of VGP on satiety. Compared to children with healthy weight, children with overweight and obesity $(\mathrm{OW} / \mathrm{OB})$ may have an impaired satiety response (Bellissimo et al. 2008a, Carnell and Wardle 2008) and an altered appetite hormone response to FI (Patel et al. 2014) that can further contribute to obesity by promoting increased FI. For example, children with OW/OB exhibit a diminished physiologic FI response following caloric preloads of whey protein (Bellissimo et al. 2008a). However, the interaction between VGP and satiety signals arising from a caloric preload in children with OW/OB is unknown. Therefore, the objective of the present study was to investigate the effects of a glucose preload (50 g) and $30 \mathrm{~min}$ of VGP on subjective emotions, subjective appetite, and subsequent FI in 9- 14 y old boys with OW/OB.

\section{METHODS}

\section{Participants}

Twenty-two boys with OW/OB ( $>85^{\text {th }}$ BMI-for age percentile) between the ages of 914 y were recruited from Halifax and Toronto via word-of-mouth, posters in areas travelled by children of this age and/or their parents, social media, and our database of previous participants. We selected boys only as our study population because in our previous work, pre-meal screen exposure did not alter FI in girls with healthy weight or OW/OB (Totosy de Zepetnek et al. 2017). The University Research Ethics Board of Mount Saint Vincent 
University and Ryerson University approved the study. This study is registered at clinicaltrials.gov (NCT0175015).

Participants were excluded if they had food sensitivities or allergies, dietary restrictions, or were taking any medications that affected FI, and those with any significant learning, behavioural, or emotional difficulties. Boys were included if they were born at healthy weight (between the $5^{\text {th }}$ and $95^{\text {th }}$ percentile for gestational age) (Kramer et al. 2001) and regularly consumed breakfast.

\section{Experimental Design}

A randomized within-subject repeated measures design was used to examine the effects of a glucose preload and VGP on subjective emotions, subjective appetite, and FI in boys with $\mathrm{OW} / \mathrm{OB}$. Participants meeting the inclusion criteria were invited to the laboratory with their parents for a screening session to obtain informed written consent (parents) and assent (participants), anthropometric and body composition measures, pizza preference (cheese or pepperoni), and to familiarize them with the study protocol. Once the participant was enrolled in the study they were then randomly assigned to a test condition order. Testing sessions were then scheduled on four separate mornings at $1000 \mathrm{~h}$ or $1100 \mathrm{~h}$, at least one week apart.

Procedures for this study are similar to our previous studies (Branton et al. 2014, Totosy de Zepetnek et al. 2017). Following a 10- 12 h overnight fast, the boys consumed a standardized breakfast (290 kcal) of skim milk (250 mL, 90 kcal; Scotsburn, NS, Canada), Honey-Nut Cheerios ${ }^{\circledR}$ cereal (26 g, 90 kcal; General Mills, Mississauga, ON, Canada) and Tropicana Orange Juice ${ }^{\circledR}(236$ mL, 110 kcal; Tropicana Products Inc, Bradenton, FL, USA) at their homes. Boys were asked to not consume any food between the standardized breakfast and the study session $2 \mathrm{~h}$ later. 
Upon arrival, a questionnaire was administered to ensure the boys had followed the pretesting protocol: consumption of the entire breakfast, no other foods consumed 10- $12 \mathrm{~h}$ prior to arrival, and a record of any medications taken. The boys consumed, within $5 \mathrm{~min}$, an equally flavoured and sweetened preload $(250 \mathrm{~mL})$ of either a sucralose control $(150 \mathrm{mg})$ or glucose (50 g available carbohydrate, 54.6 g glucose monohydrate; Grain Process Enterprises Ltd., Scarborough, ON). Both preloads were flavoured with orange sugar-free Kool-Aid drink crystals (1.1 g; Sugar Free Kool-Aid, Kraft Canada Inc. Don Mills, ON, Canada). Sucralose was used because it is not metabolized by the body and does not increase blood glucose or insulin (Duffy and Anderson 1998). The preload drinks were prepared the day before testing sessions, stored in a refrigerator in covered, opaque cups, and served chilled alongside $50 \mathrm{~mL}$ of plain water to minimize aftertaste. The boys rated the sweetness and pleasantness of the preload using visual analog scales (VAS).

After consumption of the preload drink, the boys engaged in either $30 \mathrm{~min}$ of VGP or no VGP, followed immediately by a $30 \mathrm{~min}$ ad libitum pizza lunch with a $500 \mathrm{~mL}$ bottle of water in cubicles, free of distractions. VAS were administered at baseline ( $0 \mathrm{~min})$, throughout the treatment condition $(15,30 \mathrm{~min})$, and after meal consumption (60 min).

\section{Treatment Conditions}

During the VGP condition, the boys played Angry Birds ${ }^{\mathrm{TM}}$ on a PlayStation ${ }^{\circledR} 3$ (Sony Corporation of America, New York, NY, USA) for $30 \mathrm{~min}$ in individual rooms. Angry Birds $^{\mathrm{TM}}$ was chosen as the game for its prevalence and the simplicity of the controls. During the screening session boys were asked if they had played Angry Birds ${ }^{\mathrm{TM}}$ previously and 20 of the 22 boys enrolled answered "yes." The game was pre-set to an appropriate degree of difficulty, and each participant was allowed to decide at which level he would start. At the end of the 30 min of VGP the boys ranked how much they enjoyed the VGP using a VAS. The VAS presented the question: "How well did you enjoy the video game?". The boys were 
asked to mark an "X" on a $100 \mathrm{~mm}$ line between the responses of "did not enjoy at all" to "enjoyed very much". During the no VGP condition, the boys sat in a comfortable chair and talked to a research assistant or other participants, but were not allowed to discuss food, partake in games, or engage in any form of physical activity.

\section{Experimental Procedures}

\section{Anthropometrics and Body Composition}

Height (m) using a Detecto stadiometer (Detecto, Webb City, MO) and mass (kg) using a Detecto balance (Detecto, Webb City, MO) were obtained, and age- and sex-specific BMI percentiles (Canada et al. 2004) using the Center for Disease Control's growth charts (Ogden et al. 2002) were determined. Body composition estimates were based on skinfold thickness measurements (mm) of the triceps, biceps, suprailiac and subscapular sites, obtained using Harpenden skinfold calipers (Cambridge Scientific Industries, Cambridge, MD). The sum of the four skinfold measurements were entered into age- and sex-specific regression equations to estimate fat mass (FM, $\mathrm{kg}$ and \%) and fat free mass (FFM, kg and \%) (Brook 1971).

\section{Subjective Emotions and Appetite}

VAS questionnaires were used to measure all subjective variables throughout the study including physical comfort, sweetness and palatability of the preload, pleasantness of the test meal, emotions, and average appetite (AA). Subjective emotions, as previously reported (Branton et al. 2014), were measured using a seven-item questionnaire: 1) "How aggressive do you feel?" ("not aggressive at all” to "very aggressive”), 2) "How angry do you feel?" ("not angry at all" to "very angry"), 3) "How excited do you feel?" ("not excited at all" to "very excited"), 4) "How disappointed do you feel? ("not disappointed at all” to "very disappointed"), 5) "How happy do you feel?" ("not happy at all” to "very happy"), 6) "How upset do you feel?" (“not upset at all” to "very upset”), and 7) "How frustrated do you feel?" 
("not frustrated at all" to "very frustrated"). Subjective emotion VAS were completed before treatment conditions (VGP or no VGP) (0 min), and after treatment conditions (VGP or no VGP) (30 min) (Branton et al. 2014).

Subjective AA represents four different dimensions of subjective appetite: desire to eat (DTE), hunger, fullness, and prospective food consumption (PFC) (Stubbs et al. 2000). AA was calculated using the following formula: AA score $(\mathrm{mm})=(\mathrm{DTE}+$ hunger $+[100-$ fullness] + PFC) / 4 (Bellissimo et al. 2008b, Branton et al. 2014). The subjective appetite VAS scale was administered upon arrival at baseline $(0 \mathrm{~min})$, at $15 \mathrm{~min}$, before the test meal (30 $\mathrm{min})$, and after the test meal (60 $\mathrm{min})$.

\section{Food Intake}

Pizzas (donated by McCain Foods Ltd, Florenceville, NB, Canada) were selected because of their lack of outer crust, uniform macronutrient composition, and uniform energy density (Branton et al. 2014). The pizzas were 5" in diameter and were approximately 180 kcal each. Participants were served three pizzas cut in quarters at 10 min intervals. Two pizzas of the boys' preferred type, and one of their second choice were provided on each tray (pepperoni or three cheese). The boys were asked to eat until 'comfortably full'. The weight (g) of the pizza was recorded using an analytical balance prior to serving, and the weight of the remaining pizza was recorded after each 10 min interval. The difference in weight was converted to energy (kcal) using manufacturer provided information. Water intake $(\mathrm{g})$ was determined by recording the weight of the $500 \mathrm{~mL}$ bottle with an analytical balance prior to serving and at the end of the test meal.

Cumulative energy intake (kcal) was calculated by adding the energy consumed from the preload to the energy consumed at the pizza test meal (Branton et al. 2014, Van Engelen et al. 2014). Caloric compensation (CC) was calculated for each participant using the 
formula: ([FI after sucralose control (kcal) - FI after glucose (kcal)] / [kcal in glucose] x 100) (Branton et al. 2014, Van Engelen et al. 2014).

\section{Statistical Analyses}

All data are reported as means \pm SD or SEM. The effect of treatment condition (preload and VGP as main factors) on dependent measures was assessed via a two-way ANOVA. Dependent measures included FI, water intake, pleasantness of the test meal, sweetness of the preload, and pleasantness of the preload. Change from baseline in subjective appetite, thirst, and emotions were analyzed using repeated measures ANOVA to assess the effects of preload, VGP, and time. Post hoc analyses using Tukey-Kramer's test, adjusted for multiple comparisons, were performed when significant treatment effects or interactions were found. Student's paired t-tests were used to compare VGP enjoyment and CC. Correlations between dependent measures were conducted using Pearson correlation coefficients. Statistical Analysis Systems (SAS) version 9.4 (SAS Institute Inc., Carey, NC, USA) was used for all statistical analyses, with a level of significance of $p<0.05$.

\section{RESULTS}

\section{Participants}

All twenty-two boys (mean \pm SD: age $11.9 \pm 1.6$ years; body mass $60.0 \pm 13.6 \mathrm{~kg}$ ) completed the study. All the boys were $>85^{\text {th }}$ BMI percentile for age and sex (Canada et al. 2004, Ogden et al. 2002). Baseline characteristics are presented in Table 1.

\section{Visual Analog Scales}


The subjective emotion of frustration was higher after VGP $(p<0.01)$; no other emotion was influenced by either the preload or VGP (Figure 1). There was no significant preload by VGP interaction for any subjective emotion.

Change from baseline subjective AA was not affected by preload, VGP, or their interaction, but increased over time $(p<0.05)$ (Figure 2A). Thirst changed over time $(p$ $<0.01$ ), but was not affected by preload, VGP, or their interaction (Figure 2B). There were no preload, VGP, or interaction effects observed for physical comfort, sweetness of the preload, pleasantness of the preload, pleasantness of the test meal, or enjoyment of VGP.

\section{Food and Water Intake}

FI at the meal was affected by the preload $(p<0.01)$, but not by VGP or their interaction.

The glucose preload resulted in a $103 \mathrm{kcal}$ reduction in test meal FI compared with the noncaloric Sucralose control (Table 2). Cumulative FI (preload + test meal) was affected by preload $(p<0.01)$, but not by VGP or their interaction. Cumulative energy intake was $97 \mathrm{kcal}$ higher after the glucose preload compared with the non-caloric control. CC was unaffected by VGP. Water intake was not affected by treatment condition (preload or VGP) or their interaction.

\section{Correlations}

In the glucose/VGP condition, subjective AA at 30 min was positively associated with excitement $(\mathrm{r}=0.49, p<0.05)$, happiness $(\mathrm{r}=0.50, p<0.05)$ and upset $(\mathrm{r}=0.54, p<0.05)$. In the control/no VGP condition subjective AA was positively associated with upset $(\mathrm{r}=$ $0.54, p<0.05$ ) only at $30 \mathrm{~min}$. Subjective AA scores were positively associated with FI in the 
glucose/no VGP condition at $0(\mathrm{r}=0.44, p=0.05), 15(\mathrm{r}=0.43, p<0.05)$, and $30 \mathrm{~min}(\mathrm{r}=$ $0.50, p<0.05)$, as well as in the control/VGP condition at $30 \mathrm{~min}(\mathrm{r}=0.59, p<0.01)$.

In the glucose/no VGP condition FI was positively correlated with body mass ( $r=$ $0.60, p<0.05)$, fat mass $(r=0.65, p<0.05)$, and fat free mass $(r=0.45, p<0.05)$. In the control/VGP condition fat mass was positively associated with FI $(r=0.57, p<0.05)$ and in the glucose/VGP condition body weight $(r=0.52, p<0.05)$ and fat free mass $(r=0.51, p<$ 0.05) positively correlated with FI. When glucose dose was expressed as kcal per kg of body mass, there were inverse associations with FI in both glucose conditions (no VGP: $r=-0.56$, $p<0.01$; VGP: $r=-0.57, p=<0.01$, Figure 3).

\section{DISCUSSION}

The present study aimed to determine the separate and combined effects of a caloric preload and 30 min sedentary VGP on subjective emotions, subjective appetite, and FI in 914 y old boys with OW/OB. While there was no combined effect of the preload and VGP on FI, the main separate effects were: 1) pre-meal VGP did not alter FI, and 2) a caloric preload of glucose suppressed FI, but not enough to influence cumulative FI. Collectively, these findings suggest a primary role of physiological factors in short-term regulation of FI in boys with $\mathrm{OW} / \mathrm{OB}$.

Our finding of no influence of VGP on FI in boys with OW/OB is in contrast to our observation of decreased FI following VGP in boys with healthy weight (Branton et al. 2014). Our present findings are consistent with a recent study that observed no difference in FI following 60 min of VGP compared to a sedentary control in boys with OW/OB and boys with healthy weight who were 12- 15 y old (Chaput et al. 2016). Other studies assessing the influence of VGP on FI reported no effect in 8-10 y old children with healthy weight and OW/OB (Folkvord et al. 2013), and increased FI in 15- 19 y old boys with healthy weight (Chaput et al. 2011). These findings imply body mass and age may influence the way 
children respond to screen time activities such that excess adipose tissue and increasing age are factors contributing to delayed satiation and reduced satiety signals while VGP.

Heightened emotion has been shown to influence FI; for example, 7- 8 y old children watching a video clip evoking high emotion increased FI compared to neutral emotion, suggesting more mindless eating while watching an emotional movie (Bevelander et al. 2013). In the present study VGP increased subjective frustration, however this heightened emotion did not translate to changes in FI. We reported similar increased frustration in boys with healthy weight participating in VGP (Branton et al. 2014), suggesting this is a common response in this age group and that weight status does not influence how frustration is experienced. In boys with healthy weight, however, we observed an association between positive emotions and decreased FI (Branton et al. 2014), whereas in the present study in boys with $\mathrm{OW} / \mathrm{OB}$, none of the subjective emotion scores were associated with FI. It has been hypothesized that children with healthy weight eat less in response to positive emotions, as they are able to handle challenges more effectively in a positive emotional state (i.e. the ability to resist palatable foods) (Branton et al. 2014, Evers et al. 2013, Fredrickson 2001). The degree of emotional change found in this study was modest and may not have been large enough to affect mealtime FI. However, the effect of emotions on FI in children is complex and appears to be mitigated by the environment as well as internal feelings.

Our second main finding was that the glucose preload suppressed FI at the test meal in boys with OW/OB. However, this suppression was incomplete such that cumulative FI (preload + test meal) was increased following the glucose preload compared to the sucralose control. One possible rationale is an inadequate dose of glucose to suppress FI in children with $\mathrm{OW} / \mathrm{OB}$. A fixed dose of $50 \mathrm{~g}$ of glucose was provided to all boys to replicate the amount of energy found in a single serving commercial beverage. In the present study this glucose preload resulted in low levels of CC (51\%; indicating inadequate compensation) 
compared to higher CC in healthy weight boys $(85 \%)$ in our previous study (Branton et al. 2014). FI following the glucose preload was suppressed to a greater degree in boys with healthy weight vs. OW/OB (170 kcal vs. $103 \mathrm{kcal})$; the decreased FI in boys with healthy weight represented a greater proportion of total energy within the test meal (i.e., healthy weight boys consumed $\sim 250 \mathrm{kcal}$ less at the test meal compared to OW/OB boys). Positive associations between FI and body mass following consumption of a glucose preload in both boys with OW/OB (present study) and healthy weight (Branton et al. 2014) suggest that the glucose preload produced a similar physiological response, but to a lesser magnitude in boys with OW/OB due to a proportionally smaller glucose stimulus. The inverse correlation between FI and relative glucose consumption ( $\mathrm{kcal} / \mathrm{kg}$ body mass) further support the notion that a lower glucose load may have contributed to diminished FI suppression in boys with OW/OB.

The finding of a lack of interaction between VGP and the glucose preload, combined with no main effect of VGP and a small effect of the glucose preload on FI, suggests that FI regulation is mediated primarily by physiological mechanisms in boys with OW/OB. That is, independent of VGP, the glucose preload elicited a physiological satiety response, although somewhat diminished compared to children within the healthy body weight range. A possible mechanism underlying the observed impaired satiety response of the boys with $\mathrm{OW} / \mathrm{OB}$ in this study, beyond the relatively lower dose of $\mathrm{kcal} / \mathrm{kg}$ body mass, is that gastric emptying of liquids is increased in obese individuals (Blundell et al. 2010).

The glucose preload failed to decrease subjective AA in the present study. A null effect of glucose affecting subjective AA was not due to the boys misunderstanding the VAS; children are able to understand the VAS as evidenced by the repeated observation of subjective AA decreasing after a test meal in children of this age group (Anderson et al. 2015, Bellissimo et al. 2008a). Our findings are similar with another study in children with OW/OB 
(Bellissimo et al. 2008a), and are in contrast to another study in boys with healthy weight (Branton et al. 2014). This suggests that boys with OW/OB may be unable to express the small changes in appetite that lead to small differences in subsequent FI, and/or may be attributed to the size of the glucose preload.

One limitation of the current study is that the VGP condition may not have been ideal to produce significant changes in emotion. VGP was able to influence subjective emotion; while in this instance it did not translate to differences in FI, it is possible that a greater emotional change may influence appetite or FI. Another limitation is that this study only evaluated one type of VGP, limiting the generalizability of the results. A number of physiological differences exist between healthy weight children and children with OW/OB, including the response of appetite regulatory hormones (Nguo et al. 2016) and stress hormones (Lumeng et al. 2014) to external stimuli. Two previous reports in young, healthy weight boys found no alterations in appetite regulatory hormones after VGP (Allsop et al. 2016, Chaput et al. 2011). However, future research should explore if boys with OW/OB respond differently. The effect of VGP on the stress response in children appears to be mitigated by the type of game played (e.g. violent vs non-violent) (Gentile et al. 2017). Future studies should evaluate other types of screen time activities, types of video games (e.g. violent, multiplayer, active) and screen time activities in different contexts (e.g. with peers, in a competitive environment) in children of differing weight statuses. In addition, studies should aim to understand the effect of VGP timing, particularly before an evening meal or within a meal, and to quantify the effects of VGP on caloric intake for the rest of the day. In conclusion, the results of the present study suggest a complex interaction between VGP and body mass status when contrasted to previous research exploring the effect of screen time on FI in boys with normal weight (Bellissimo et al. 2007). Our findings indicate 
that, unlike boys with healthy weight (Branton et al. 2014), boys with OW/OB do not reduce their FI following 30 min of pre-meal VGP and exhibit impaired CC after a glucose preload.

Conflict of interest: The authors have no conflicts of interest to report. 


\section{REFERENCES}

Adolphus K, Bellissimo N, Lawton CL, Ford NA, Rains TM, Totosy de Zepetnek J, et al.

2017. Methodological Challenges in Studies Examining the Effects of Breakfast on

Cognitive Performance and Appetite in Children and Adolescents. Adv. Nutr. 8(1):184S-

96S. $\quad 10.3945 /$ an.116.012831

Allsop S, Green BP, Dodd-Reynolds CJ, Barry G, Rumbold PL. 2016. Comparison of shortterm energy intake and appetite responses to active and seated video gaming, in 8-11-yearold boys. Br. J. Nutr. 115(6):1117-25. 10.1017/S0007114515005437

Anderson GH, Khodabandeh S, Patel B, Luhovyy BL, Bellissimo N, Mollard RC. 2015. Mealtime exposure to food advertisements while watching television increases food intake in overweight and obese girls but has a paradoxical effect in boys. Appl.

Physiol. $\quad$ Nutr. Metab. 40(2):162-7. 10.1139/apnm-2014-0249

Bellissimo N, Desantadina MV, Pencharz PB, Berall GB, Thomas SG, Anderson GH. 2008a.

A comparison of short-term appetite and energy intakes in normal weight and obese

boys following glucose and whey-protein drinks. Int. J. Obes. (Lond). 32(2):362-71.

\subsection{8/sj.ijo.0803709}

Bellissimo N, Pencharz PB, Thomas SG, Anderson GH. 2007. Effect of television viewing at mealtime on food intake after a glucose preload in boys. Pediatr. Res. 61(6):745-9.

\section{$\underline{10.1203 / \mathrm{pdr} .0 \mathrm{~b} 013 \mathrm{e} 3180536591}$}

Bellissimo N, Thomas SG, Pencharz PB, Goode RC, Anderson GH. 2008b. Reproducibility of short-term food intake and subjective appetite scores after a glucose preload, ventilation threshold, and body composition in boys. Appl. Physiol. Nutr. and Metab. 33(2):326-37. 10.1139/H07-194 
Bevelander KE, Meiselman HL, Anschutz DJ, Engels RCME. 2013. Television watching and the emotional impact on social modeling of food intake among children. Appetite. 63:706. $\quad$ 10.1016/j.appet.2012.12.015

Blundell J, de Graaf C, Hulshof T, Jebb S, Livingstone B, Lluch A, et al. 2010. Appetite control: methodological aspects of the evaluation of foods. Obes. Rev. 11(3):251-70. $\underline{10.1111 / j .1467-789 X .2010 .00714 . X}$ Branton A, Akhavan T, Gladanac B, Pollard D, Welch J, Rossiter M, et al. 2014. Pre-meal video game playing and a glucose preload suppress food intake in normal weight boys. Appetite. 83:256-62. 10.1016/j.appet.2014.08.024

Brook CGD. 1971. Determination of Body Composition of Children from Skinfold Measurements. Arch. Dis. Child. 46(246):182-\&.

Brunstrom JM, Mitchell GL. 2006. Effects of distraction on the development of satiety. Br. J. Nutr. 96(4):761-9.

Cameron JD, Maras D, Sigal RJ, Kenny GP, Borghese MM, Chaput JP, et al. 2016. The mediating role of energy intake on the relationship between screen time behaviour and body mass index in adolescents with obesity: The HEARTY study. Appetite.

\section{7:437-44. $\quad \underline{\text { 10.1016/j.appet.2016.08.101 }}$}

Dietitians of Canada; Canadian Paediatric Society; College of Family Physicians of Canada; Community Health Nurses Association of Canada. 2004. The use of growth charts for assessing and monitoring growth in Canadian infants and children. Can. J. Diet. Pract. Res. 65(1):22-32.

Carnell S, Wardle J. 2008. Appetitive traits and child obesity: measurement, origins and implications for intervention. Proc. Nutr. Soc. 67(4):343-55. $\underline{10.1017 / \mathrm{S} 0029665108008641}$ 
Carson V, Janssen I. 2012. Neighborhood disorder and screen time among 10-16 year old Canadian youth: a cross-sectional study. Int. J. Behav. Nutr. Phys. Act. 9:66. $\underline{10.1186 / 1479-} \underline{5868-9-66}$

Carvalhal MM, Padez MC, Moreira PA, Rosado VM. 2007. Overweight and obesity related to activities in Portuguese children, 7-9 years. Eur. J. Public. Health. 17(1):42-6. $\underline{10.1093 / \text { eurpub/ck1093 }}$

Chaput JP, Tremblay A, Pereira B, Boirie Y, Duclos M, Thivel D. 2016. Food intake response to exercise and active video gaming in adolescents: effect of weight status. Br. J. Nutr. 115(3):547-53. 10.1017/S0007114515004602

Chaput JP, Visby T, Nyby S, Klingenberg L, Gregersen NT, Tremblay A, et al. 2011. Video game playing increases food intake in adolescents: a randomized crossover study. Am. J. Clin. Nutr. 93(6):1196-203. 10.3945/ajcn.110.008680

Duffy VB, Anderson GH. 1998. Position at the American Dietetic Association: Use of nutritive and nonnutritive sweeteners. J. Am. Diet. Assoc. 98(5):580-7. Eagle TF, Sheetz A, Gurm R, Woodward AC, Kline-Rogers E, Leibowitz R, et al. 2012. Understanding childhood obesity in America: linkages between household income, community resources, and children's behaviors. Am. Heart. J. 163(5):836-43. 10.1016/j.ahj.2012.02.025

Epstein LH, Temple JL, Roemmich JN, Bouton ME. 2009. Habituation as a determinant of human food intake. Pyschol. Rev. 116(2):384-407. 10.1037/a0015074

Evers C, Adriaanse M, de Ridder DTD, de Witt Huberts JC. 2013. Good mood food. Positive emotion as a neglected trigger for food intake. Appetite. 68:1-7. 10.1016/j.appet.2013.04.007

Foeher UG, Rideout, V., Roberts, D.F., . Generation M2. Media in the lives of 8-to 18-yearolds. Menlo Park, CA: 2010. 
Folkvord F, Anschutz DJ, Buijzen M, Valkenburg PM. 2013. The effect of playing advergames that promote energy-dense snacks or fruit on actual food intake among children. Am. J. Clin. Nutr. 97(2):239-45. 10.3945/ajen.112.047126

Fredrickson BL. 2001. The role of positive emotions in positive psychology. The broadenand- build theory of positive emotions. Am. Psychol. 56(3):218-26.

Gentile DA, Bender PK, Anderson CA. 2017. Violent video game effects on salivary cortisol, arousal, and aggressive thoughts in children. Comput. Human. Behav. 70:39-43. $\underline{10.1016 / \mathrm{j} . \operatorname{chb} .2016 .12 .045}$

Gribbon A, McNeil J, Jay O, Tremblay MS, Chaput JP. 2015. Active video games and energy balance in male adolescents: a randomized crossover trial. Am. J. Clin. Nutr. 101(6):1126-34. 10.3945/ajen.114.105528

Hands BP, Chivers PT, Parker HE, Beilin L, Kendall G, Larkin D. 2011. The associations between physical activity, screen time and weight from 6 to 14 yrs: the Raine Study. J Sci. Med. Sport. 14(5):397-403. 10.1016/j.jsams.2011.03.011

Kramer MS, Platt RW, Wen SW, Joseph KS, Allen A, Abrahamowicz M, et al. 2001. A new and improved population-based Canadian reference for birth weight for gestational age. Pediatrics. 108(2):E35.

Lumeng JC, Miller A, Peterson KE, Kaciroti N, Sturza J, Rosenblum K, et al. 2014. Diurnal cortisol pattern, eating behaviors and overweight in low-income preschool-aged children. Appetite. 73:65-72. 10.1016/j.appet.2013.10.016 Mellecker RR, Lanningham-Foster L, Levine JA, McManus AM. 2010. Energy intake during activity enhanced video game play. Appetite. 55(2):343-7.

$\underline{10.1016 / j . a p p e t .2010 .07 .008}$ 
Mitchell JA, Rodriguez D, Schmitz KH, Audrain-McGovern J. 2013. Greater screen time is associated with adolescent obesity: a longitudinal study of the BMI distribution from Ages 14 to 18. Obesity. (Silver Spring). 21(3):572-5. 10.1002/oby.20157

Nguo K, Walker KZ, Bonham MP, Huggins CE. 2016. Systematic review and meta-analysis of the effect of meal intake on postprandial appetite-related gastrointestinal hormones in obese children. Int. J. Obes. (Lond). 40(4):555-63. 10.1038/ijo.2015.256

Ogden CL, Kuczmarski RJ, Flegal KM, Mei Z, Guo S, Wei R, et al. 2002. Centers for Disease $\quad$ Control and Prevention 2000 growth charts for the United States: Improvements to the 1977 National Center for Health Statistics version. Pediatrics. 109(1):45-60. 10.1542/peds.109.1.45

Patel BP, Anderson GH, Vien S, Bellissimo N, McCrindle BW, Hamilton JK. 2014. Obesity, sex and pubertal status affect appetite hormone responses to a mixed glucose and whey protein drink in adolescents. Clin. Endocrinol. (Oxf). 81(1):63-70. 10.1111/cen.12403 Stettler N, Signer TM, Suter PM. 2004. Electronic games and environmental factors associated with childhood obesity in Switzerland. Obes. Res. 12(6):896-903. $\underline{10.1038 / \text { oby.2004.109 }}$

Strasburger VC. 2004. Children, adolescents, and the media. Curr. Probl. Pediatr. Adolesc. Health. Care. 34(2):54-113. 10.1016/j.cppeds.2003.08.001

Stubbs RJ, Hughes DA, Johnstone AM, Rowley E, Reid C, Elia M, et al. 2000. The use of visual analogue scales to assess motivation to eat in human subjects: a review of their reliability and validity with an evaluation of new hand-held computerized systems for temporal tracking of appetite ratings. Br. J. Nutr. 84(4):405-15.

Totosy de Zepetnek JO, Pollard D, Welch JM, Rossiter M, Faghih S, Bellissimo N. 2017.

Pre- meal screen-time activities increase subjective emotions, but not food intake in young girls. Appetite. 111:32-7. 10.1016/j.appet.2016.12.025 
Tremblay MS, Leblanc AG, Janssen I, Kho ME, Hicks A, Murumets K, et al. 2011. Canadian sedentary behaviour guidelines for children and youth. Appl. Physiol. Nutr. Metab. 36(1):59-64; 5-71. 10.1139/H11-012

Turel O, Romashkin A, Morrison KM. 2017. A model linking video gaming, sleep quality, sweet drinks consumption and obesity among children and youth. Clin. Obes. 7(4):191-8. $\underline{10.1111 / \text { cob. } 12191}$

Van Engelen M, Khodabandeh S, Akhavan T, Agarwal J, Gladanac B, Bellissimo N. 2014. Effect of sugars in solutions on subjective appetite and short-term food intake in 9- to

14- $\quad$ year-old normal weight boys. Eur. J. Clin. Nutr. 68(7):773-7. 10.1038/ejen.2014.33 
Table 1. Baseline Characteristics

\begin{tabular}{lc}
\hline Variable & Mean \pm SD $(\mathrm{n}=22)$ \\
\hline Age $(\mathrm{y})$ & $11.9 \pm 1.6$ \\
Body mass $(\mathrm{kg})$ & $60.0 \pm 13.6$ \\
Height $(\mathrm{m})$ & $1.54 \pm 0.1$ \\
BMI percentile & $94.3 \pm 3.9$ \\
Fat mass $(\mathrm{kg})^{2}$ & $19.5 \pm 6.6$ \\
Fat mass $(\%)^{2}$ & $31.9 \pm 6.0$ \\
Fat-free mass $(\mathrm{kg})^{2}$ & $40.5 \pm 8.7$ \\
Fat-free mass $(\%)^{2}$ & $68.1 \pm 6.0$ \\
\hline
\end{tabular}

${ }^{1}$ Based on the Center for Disease Control growth charts (Ogden et al. 2002).

${ }^{2}$ Estimated from the sum of skin folds at four points (Brook 1971).

Table 2. Effect of preload and video game playing (VGP) in boys

No VGP VGP




\begin{tabular}{lcccc}
\hline & Control & Glucose & Control & Glucose \\
Food intake ${ }^{1}(\mathrm{kcal})$ & $1093 \pm 67$ & $1021 \pm 75$ & $1187 \pm 72$ & $1054 \pm 62$ \\
Cumulative energy intake ${ }^{2}(\mathrm{kcal})$ & $1093 \pm 67$ & $1221 \pm 75$ & $1187 \pm 72$ & $1254 \pm 62$ \\
Water intake $(\mathrm{g})^{3}$ & $328 \pm 51$ & $311 \pm 30$ & $333 \pm 43$ & $296 \pm 47$ \\
Caloric compensation $(\%)^{4}$ & - & $36 \pm 34$ & - & $66 \pm 34$ \\
Sweetness of preload $(\mathrm{mm})^{5}$ & $81 \pm 3$ & $80 \pm 3$ & $74 \pm 4$ & $77 \pm 4$ \\
Pleasantness of preload $(\mathrm{mm})^{6}$ & $71 \pm 6$ & $73 \pm 4$ & $72 \pm 5$ & $67 \pm 7$ \\
Pleasantness of test meal $(\mathrm{mm})^{7}$ & $88 \pm 4$ & $82 \pm 3$ & $88 \pm 3$ & $80 \pm 5$ \\
${\text { VGP enjoyment }(\mathrm{mm})^{8}}$ & - & - & $86 \pm 3$ & $84 \pm 4$ \\
\hline
\end{tabular}

Data are presented as means \pm SEM $(n=22)$.

${ }^{1}$ Food intake was affected by preload $(p<0.01)$, but not VGP $(p=0.09)$, or a preload by VGP interaction ( $p=0.60$, Two-way ANOVA).

${ }^{2}$ Cumulative food intake (test meal + preload) was affected by preload $(p<0.01)$, but not $\operatorname{VGP}(p=0.09)$ or a preload by VGP interaction $(p=0.60$, Two-way ANOVA).

${ }^{3}$ Water intake was not affected by preload $(p=0.44)$, VGP $(p=0.80)$, or their interaction ( $p$ $=0.66$, Two-way ANOVA).

${ }^{4}$ Caloric compensation was not affected by VGP $(p=0.54$, Paired t-test $)$.

${ }^{5}$ Sweetness of the preload was not affected by preload $(p=0.71)$ VGP $(p=0.11)$, or a preload by VGP interaction ( $p=0.53$, Two-way ANOVA).

${ }^{6}$ Pleasantness of the preload was not affected by preload $(p=0.81)$, VGP $(p=0.59)$, or a preload by VGP interaction ( $p=0.48$, Two-way ANOVA).

${ }^{7}$ Pleasantness of the pizza provided at the test meal was not affected by preload $(p=0.20)$, $\operatorname{VGP}(p=0.46)$, or their interaction ( $p=0.76$, Two-way ANOVA).

${ }^{8}$ Enjoyment of the VGP was not affected by preload ( $p=0.59$, Paired t-test). 
Figure 1. Effect of preload and video game playing on change from baseline to $30 \mathrm{~min}$ subjective frustration ratings. Data are presented as means \pm SEM $(n=22)$. Frustration was higher after VGP $(p<0.01)$ but there was no effect of preload $(p=0.30)$ or a preload by VGP interaction ( $\mathrm{p}=0.08$, Two-way ANOVA).

Figure 2. Effect of preload and video game playing on change from baseline subjective average appetite (Panel A) and thirst (Panel B) scores. Data are presented as means \pm SEM (n =22). Test meal began at $30 \mathrm{~min}$. Panel A: Change from baseline average appetite was 
affected by time $(p<0.05)$ but, not preload $(p=0.13)$, VGP $(p=0.50)$, or a VGP by preload interaction ( $p=0.72$, Three-way ANOVA). Panel B: Change from baseline thirst was affected by time $(p<0.01)$, but not preload $(p=0.11)$, VGP $(p=0.18)$, or a preload by VGP interaction ( $p=0.52$, Three-way ANOVA).

Figure 3. Association between glucose dose (kcal/kg body mass) and food intake after no video game playing (VGP) (Panel A) and VGP (Panel B). Panel A: kcal of glucose per kg body mass was inversely associated with FI in the no VGP test condition $(r=-0.56, p<$ 0.01)). Panel B: kcal of glucose per kg body mass was inversely associated with FI in the VGP test condition $(r=-0.57, p<0.01)$. 


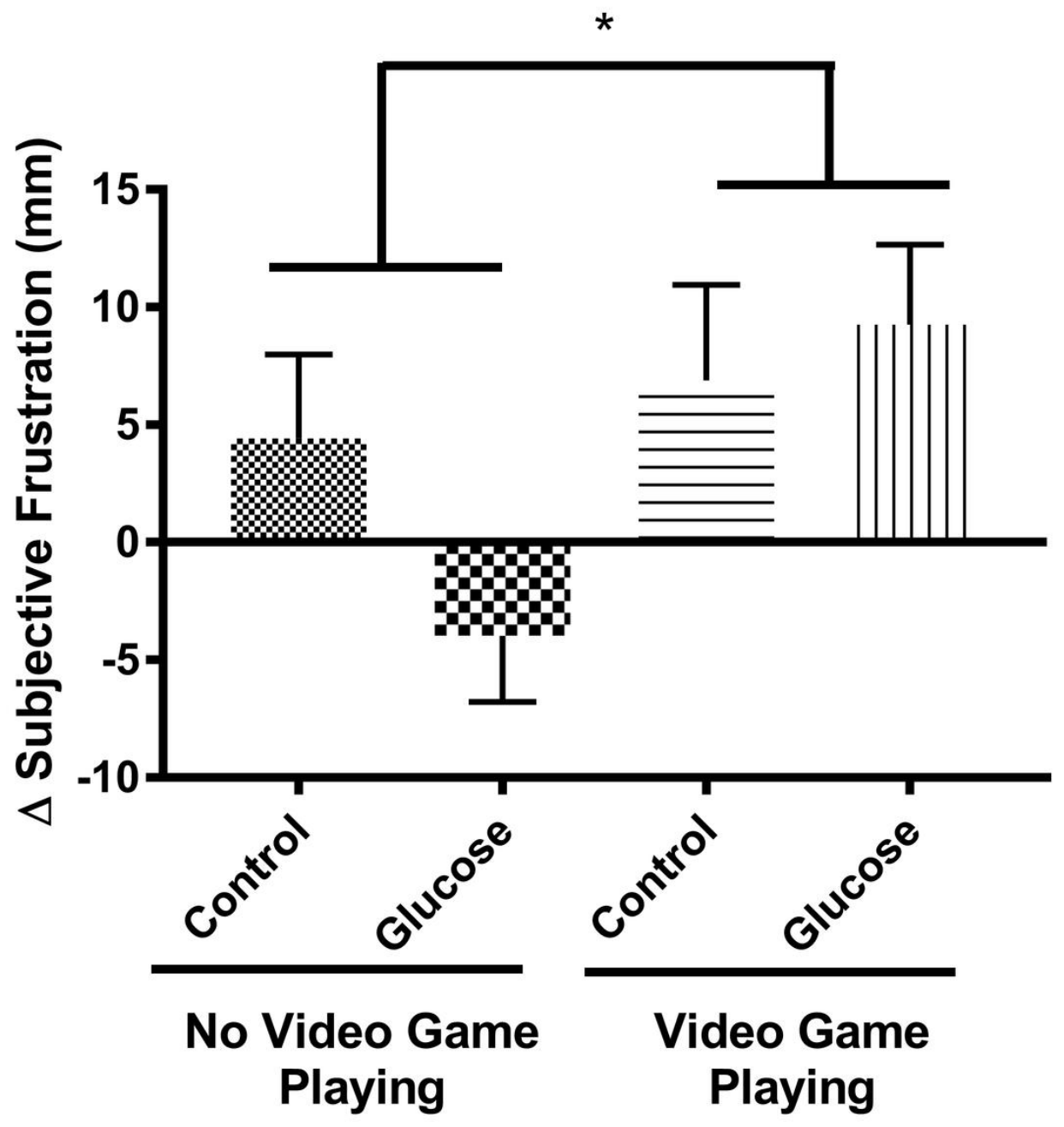

$96 \times 103 \mathrm{~mm}(300 \times 300 \mathrm{DPI})$ 

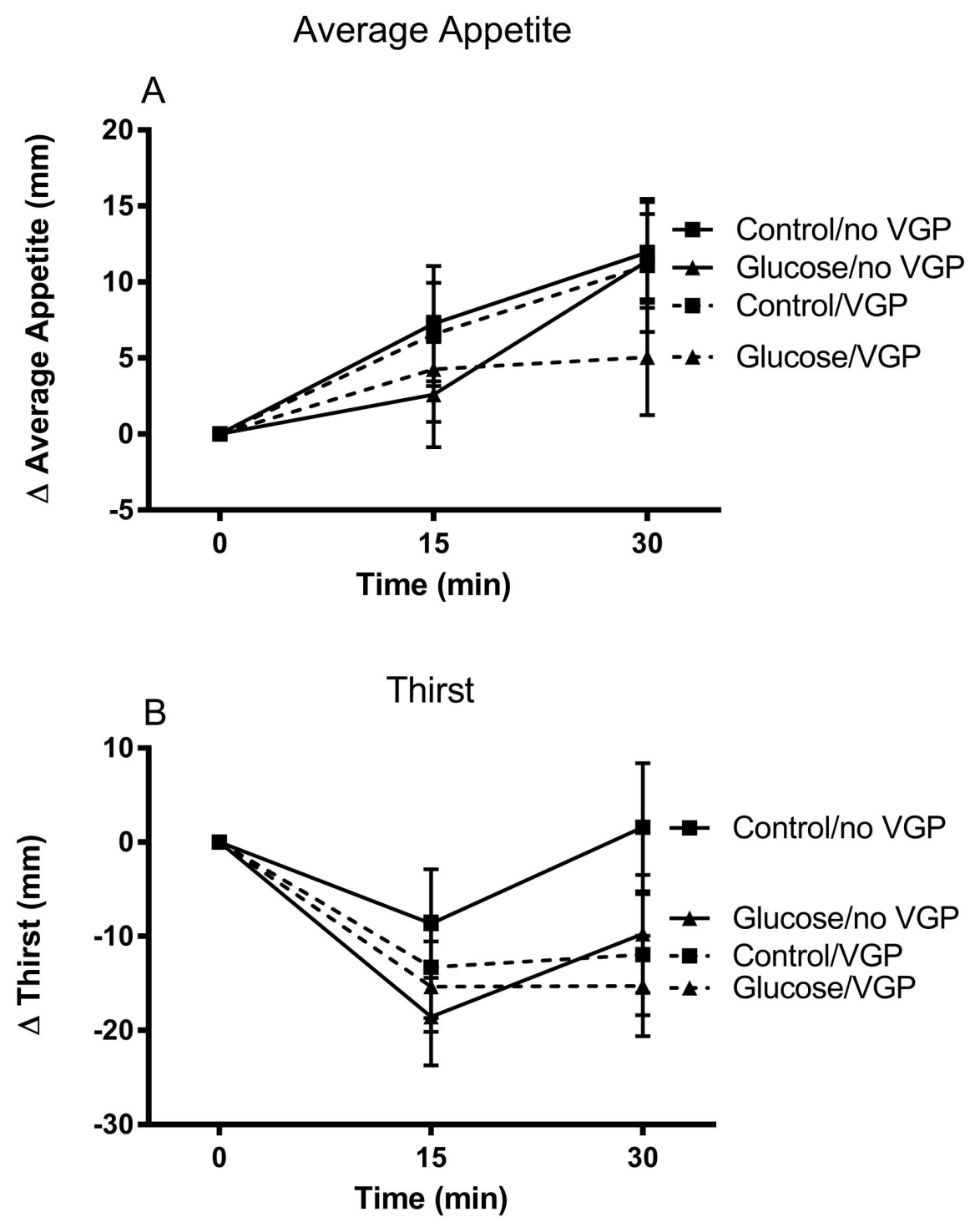

$170 \times 210 \mathrm{~mm}(300 \times 300 \mathrm{DPI})$ 

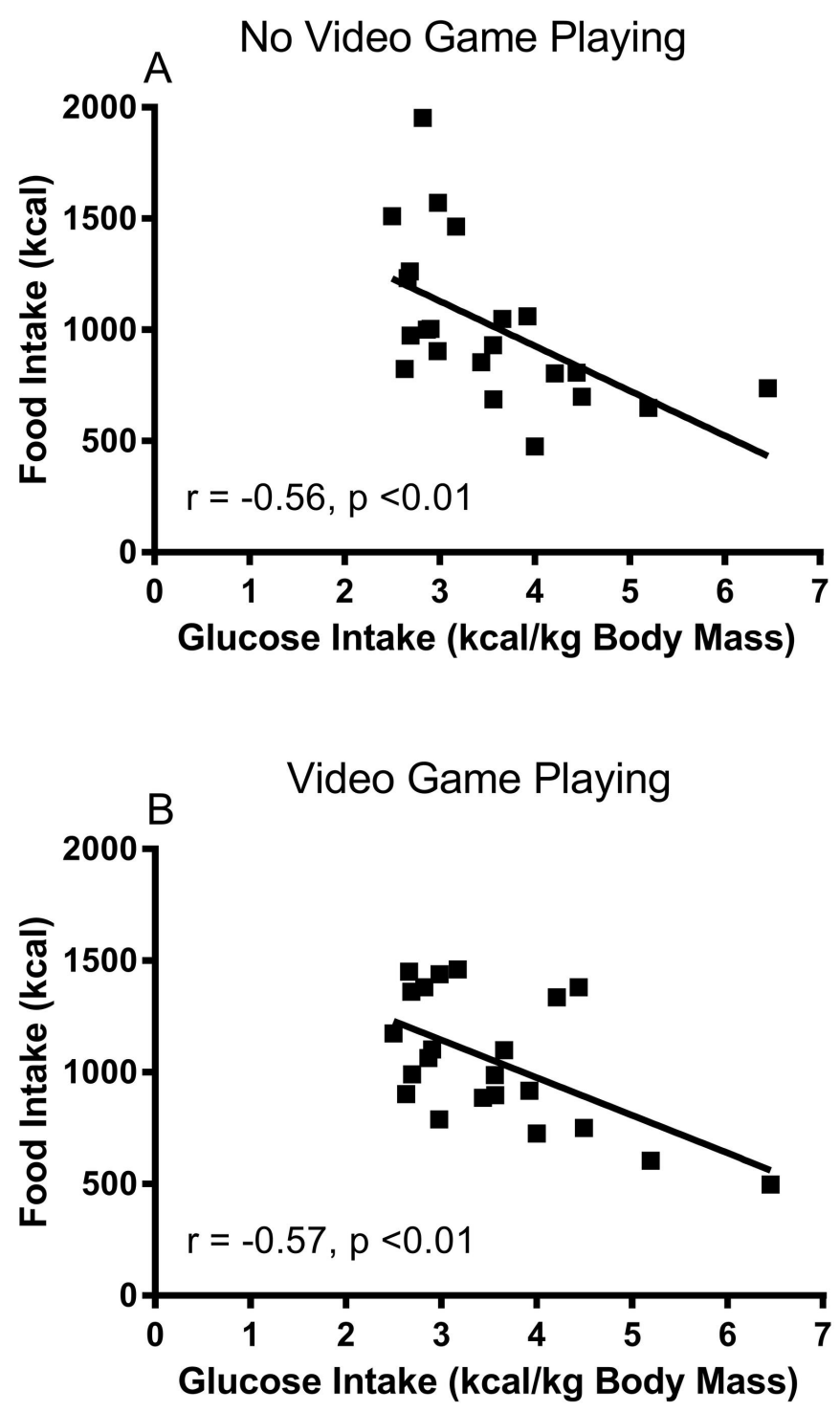

$165 \times 249 \mathrm{~mm}(300 \times 300$ DPI $)$ 